\title{
Amino Acid-Bearing ROMP Polymers with a Stereoregular Backbone
}

\author{
Jae Chul Lee, Kathlyn A. Parker, and Nicole S. Sampson \\ Department of Chemistry, Stony Brook University, Stony Brook, NY 11794-3400
}

"Living" polymerizations provide materials with well-defined chain lengths and narrow molecular weight distributions (polydispersity indices or PDIs). They also allow the preparation of block polymers. Among the general classes of living polymerizations, ring opening metathesis polymerization (ROMP) has been broadly applied for the synthesis of materials with interesting physical properties ${ }^{1}$ and biological activities. ${ }^{2,3}$

Although ROMP polymers have been prepared from many strained cycloalkenes and their derivatives, ${ }^{4}$ norbornenes and oxanorbornenes are used for the preparation of peptide- and carbohydrate-bearing multivalent ROMP polymers. 3,5 These monomers, substituted on the 5position or on the 5- and 6-positions of the norbornene ring, are the most synthetically accessible monomers that metathesize efficiently. However, in these systems, stereocontrol of the polymerization reaction is not always possible. For example, ruthenium-catalyzed polymerization of 5-substituted norbornene and oxanorbornene monomers provides stereochemically heterogeneous materials. ${ }^{6}$ Each monomeric unit contributes three stereochemical variables that are not controlled in the chain extension step. ${ }^{7}$ Therefore it is difficult to correlate the physical or biological properties of these polymers with specific structural features.

For our studies of bi- and multidentate binding to cell surfaces, 3,8 we wished to employ multivalent peptide-bearing polymers in which structural ambiguities were minimized. We considered the design of a ROMP monomer that would provide polymers that were translationally invariant. A desirable monomer might be an unbridged, strained cyclic olefin that contains no chiral centers. A 1-substituted cyclobutene suggested itself as a possible solution to this problem. If the resulting polymer were to contain no head-to-tail or E/Z double bond ambiguities, it would meet our criterion.

We postulated that cyclobutene carboxylic acid derivatives might undergo rutheniumcatalyzed ROMP with high regiochemical and geometric preferences. The literature offers several examples of the ROMP and ROM (ring opening metathesis) of substituted cyclobutenes ${ }^{9-12}$ including three examples in which the substrate is a 1-substituted cyclobutene. ${ }^{12}$ Indeed, with the $(\mathrm{CO})_{5} \mathrm{WC}\left(\mathrm{C}_{6} \mathrm{H}_{5}\right)_{2}$ catalyst, Katz and coworkers produced translationally invariant (all head-to-tail, $E$-olefinic) polymer. ${ }^{12 \mathrm{~d}}$ Nonetheless, it was not obvious that the more functional group-tolerant ruthenium catalysts would give analogous results with related monomers.

In this communication, we describe the polymerization of cyclobutene-1-carboxamide $\mathbf{1}$ with the Grubbs precatalyst 2,notable for its fast initiation rates and the narrow dispersities of the

kathlyn.parker@stonybrook.edu, nicole.sampson@stonybrook.edu.

Supporting Information available: Experimental details including synthetic procedures, spectroscopic data, gel permeation data and MALDI-TOF mass analysis. This material is available free of charge via the internet at http://pubs.acs.org. 
materials it provides. ${ }^{13}$ The polymers that we obtained, models for peptide-bearing, multivalent tools for mechanistic studies, had low to moderate PDIs and were translationally invariant.

A preliminary experiment indicated the regiochemistry of the metathesis of the substrate with the ruthenium carbene $\mathbf{2}$. Thus, substrate $\mathbf{1}$, when treated with 1.0 equivalent of initiator $\mathbf{2}$ afforded the ring-opened metathesis product $\mathbf{3}$ as a single regioisomer (Scheme 1). This result is consistent with a mechanism in which the ruthenium carbene adds to the substrate to form metallocyclobutene $\mathbf{4}$, which then undergoes ring opening to the carbonyl-substituted ruthenium carbene $\mathbf{5}$. When ethyl vinyl ether is added, a second metathesis cycle leads to the formation of Fischer carbene $\mathbf{6}$ and 1,1-disubstituted alkene 3 as a 1:1.4 mixture of $Z$ and $E$ styrene olefins.

Next we performed an experiment designed to afford the 10-mer 7. Catalyst was stirred with 10 equivalents of substrate $\mathbf{1}$ and quenching was effected by addition of ethyl vinyl ether. The ${ }^{1} \mathrm{H}$ NMR spectrum of the product exhibited a broad signal for the aromatic group centered at $7.29 \mathrm{ppm}$, a broad signal of olefinic protons centered at $6.22 \mathrm{ppm}$ and two small olefinic proton signals centered at 5.56 and $5.39 \mathrm{ppm}$. Comparison to ${ }^{1} \mathrm{H}$ NMR spectra of model compounds (Supporting Information) revealed that the peak at $6.22 \mathrm{ppm}$ corresponds to the proton at the $\beta$-position of the unsaturated amide and two styrenyl protons, and the peaks at 5.56 and $5.39 \mathrm{ppm}$ correspond to the terminal vinyl group. The relative intensities of the signals were 5:11:1:1 (7.29, 6.22, 5.56 and $5.39 \mathrm{ppm})$, a ratio that is fully consistent with the internally homogeneous structure 7 in which the trisubstituted olefinic bonds have the $E$ - and not the Zconfiguration. A contribution from protons on a 1,2-dialkyl olefin, which would appear at 5.3 $-5.5 \mathrm{ppm}$, could not be discerned.

Longer polymers, 18-mer (8), 35-mer (9) and 50-mer (10), were prepared by similar experiments with different ratios of catalyst to monomer. The ${ }^{1} \mathrm{H}$ NMR spectrum of each showed a peak at $6.22 \mathrm{ppm}$, the integration of which increased in proportion to the length of the polymer; no new vinyl peaks appeared.

Additional evidence for the structures of the polymers was obtained by ${ }^{13} \mathrm{C}$ NMR spectroscopy. In the case of 7, two amide-substituted alkene carbon signals were observed at 136.4 and 136.2 $\mathrm{ppm}$. Likewise, the ${ }^{13} \mathrm{C}$ NMR spectra for longer polymers showed two distinct peaks at 136.4 and $136.2 \mathrm{ppm}$. In order to clarify the identities of the two peaks, an APT (Attached Proton Test) experiment was performed on polymer $\mathbf{8}$. The carbon with a peak at $136.4 \mathrm{ppm}$ has a single hydrogen attached and the carbon with a peak at $136.2 \mathrm{ppm}$ bears no hydrogens. This experiment confirms that the structure of the polymer is composed of repeating $\alpha, \beta$ unsaturated amide units. In total the ${ }^{1} \mathrm{H}$ NMR, ${ }^{13} \mathrm{C}$ NMR and APT spectra demonstrate that the ROMP of cyclobutenecarboxylic amide $\mathbf{1}$ is highly regio- and stereoselective and that it yields a headto-tail ordered polymer (Scheme 2) in which there are no ambiguities of tacticity.

Along with stereoregularity, polydispersity is an important characteristic of well-defined polymers. We measured the polydispersity index (PDI) of each of our polymers by gel permeation chromatography (GPC) with polystyrene standards (PSS). For each of the polymers, the PSS $M_{n}$ was larger than the value calculated from the NMR data. This result is consistent with the Benoit factor for substituted 1,4-polybutadienes. ${ }^{10 a}$ For each polymer, the PDI was low to moderate and the molecular weight distribution was monomodal (Table 1 and data not shown). In the preparations of larger polymers it was necessary to warm the reaction mixtures in order to effect complete reaction; the higher temperature presumably accounts for the larger PDIs. A plot of average molecular weight versus monomer consumed was linear; this result was consistent with a living polymerization and the absence of chain transfer (data in Supporting Information). 
Seeking more accurate molecular weight data for our polymers, we examined the MALDITOF spectrum of polymer 7 (Figure 1).

The molecular ions and monomer repeats $(+169)$ are consistent with the assigned structure. The calculated $M_{n}$ indicates that the average length of the polymer is that of an 11-mer, in close agreement with our NMR data. The PDI is 1.15 in accord with the GPC data.

Thus, the ROMP of cyclobutenecarboxamide 1 was regio-and stereoselective and afforded functionalized polymers with polydispersities ranging from 1.2-1.6. Related polymers should provide the basis for applications in both materials and chemical biology when well-defined stereoregular structures are advantageous. Further study is in progress to fully characterize the ROMP of cyclobutene amides and other unexploited monomers.

\section{Supplementary Material}

Refer to Web version on PubMed Central for supplementary material.

\section{Acknowledgment}

This research was supported by NIH grants R01HD38519 (N.S.), S10RR021008 (N.S.), and CA87503 (K.A.P.), and NSF grant CHE0131146 (NMR). We thank Dr. James Marecek for his assistance with NMR spectroscopy.

\section{References}

1. a Komiya Z, Pugh C, Schrock RR. Macromolecules 1992;25:6586-6592. b Royappa AT, Saunders RS, Rubner MF, Cohen RE. Langmuir 1998;14:6207-6214. c Lynn DM, Mohr B, Grubbs RH. J. Am. Chem. Soc 1998;120:1627-1628.

2. a Gordon EJ, Gestwicki JE, Strong LE, Kiessling LL. Chem. Biol 2000;7:9-16. [PubMed: 10662681] b Gestwicki JE, Cairo CW, Strong LE, Oetjen KA, Kiessling LL. J. Am. Chem. Soc 2002;124:1492214933. [PubMed: 12475334]

3. a Roberts KS, Konkar S, Sampson NS. ChemBioChem 2003;4:1229-1231. [PubMed: 14613117] b Baessler K, Lee Y, Roberts KS, Facompre N, Sampson NS. Chem. Biol. 2006in press

4. Black, G.; Maher, D.; Risse, W. Living Ring-Opening Olefin Metathesis Polymerization.. In: Grubbs, RH., editor. Handbook of Metathesis. 3. Wiley-VCH; Weinheim: 2003. p. 2-71.

5. a Nomura K, Schrock RR. Macromolecules 1996;29:540-545. b Biagini SCG, Davies RG, Gibson VC, Giles MR, Marshall EL, North M, Robson DA. Chem. Commun 1999:235-236.Kiessling, LL.; Owen, RM. Syntheses and Applications of Bioactive Polymers Generated by Ring-Opening Metathesis Polymerization.. In: Grubbs, RH., editor. Handbook of Metathesis. 3. Wiley-VCH; Weinheim: 2003. p. 180-225.

6. a Amir-Ebrahimi V, Corry DA, Hamilton JG, Thompson JM, Rooney JJ. Macromolecules 2000;33:717-724. b Maynard HD, Okada SY, Grubbs RH. Macromolecules 2000;33:6239-6248.

7. Schueller CM, Manning DD, Kiessling LL. Tetrahedron Lett 1996;37:8853-8856.

8. Roberts KS, Sampson NS. Org. Lett 2004;6:3253-5. [PubMed: 15355025]

9. 3-substituted cyclobutenes: a Maughon BR, Weck M, Mohr B, Grubbs RH. Macromolecules 1997;30:257-265. b Maughon BR, Grubbs RH. Macromolecules 1997;30:3459-3469.

10. 3,4-disubstituted cyclobutenes: a Lapinte V, de Fremont P, Montembault VR, Fontaine L. Macromol. Chem. Phys 2004;205:1238-1245. b Perrott MG, Novak BM. Macromolecules 1996;29:1817-1823. c Snapper ML, Tallarico JA, Randall ML. J. Am. Chem. Soc 1997;119:1478-1479. and Tallarico JA, Randall ML, Snapper ML. Tetrahedron 1997;53:16511-20.

11. 3,3-disubstituted cyclobutenes: a Wu Z, Grubbs RH. Macromolecules 1995;28:3502-3508. b Alder RW, Allen PR, Khosravi E. J. Chem. Soc., Chem. Commun 1994:1235-1236.

12. 1-substituted cyclobutenes: a Katz TJ, McGinnis J, Altus C. J. Am. Chem. Soc 1976;98:606-608. b Wilson SR, Schalk DE. J. Org. Chem 1976;41:3928-3929. c Kormer VA, Dolinskaya ER, 
Khatchaturov AS. Makromol. Chem. Rapid Commun 1980;1:531-535. d Katz TJ, Lee SJ, Shippey MA. J. Mol. Catal 1980;8:219-226. e Feng J, Szeimies G. Eur. J. Org. Chem 2002:2942-2947.

13. Love JA, Morgan JP, Trnka TM, Grubbs RH. Angew. Chem. Int. Ed. Engl 2002;41:4035-4037. [PubMed: 12412073] 

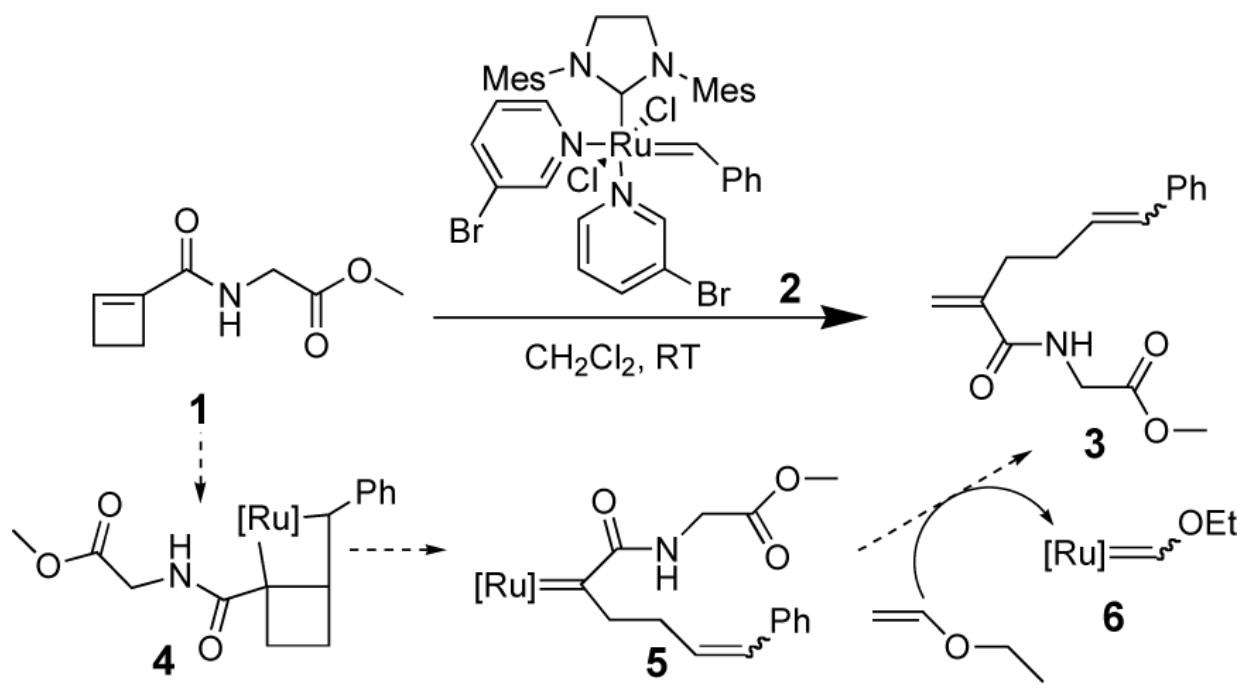

Scheme 1.

Ring-opening metathesis one-mer formation. 


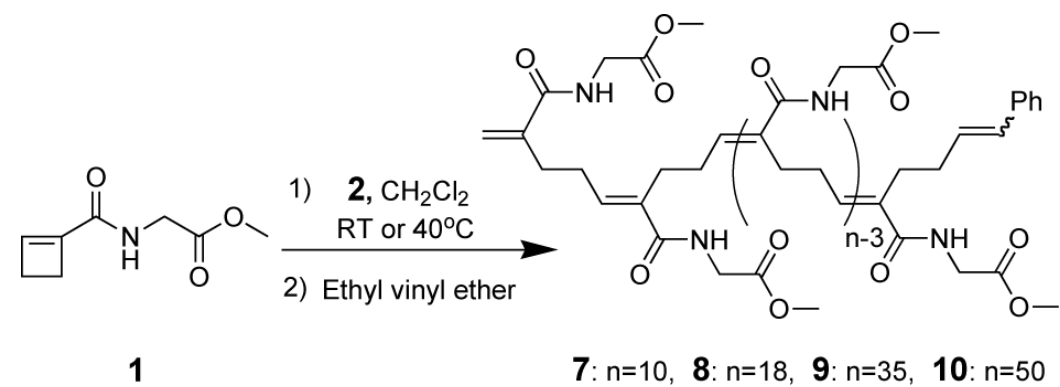

Scheme 2.

Ring-opening metathesis polymer formation. 


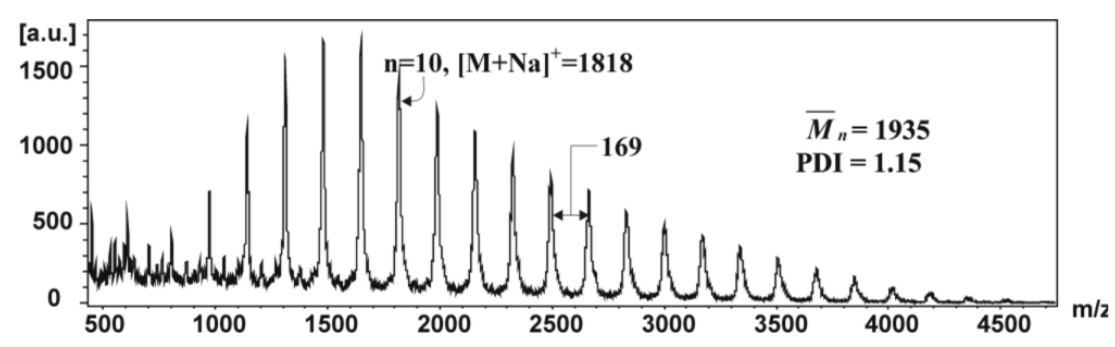

Figure 1.

MALDI-TOF mass spectrum of 7 (linear, positive ion mode) with 5-chloro-2mercaptobenzothiazole as the matrix. 


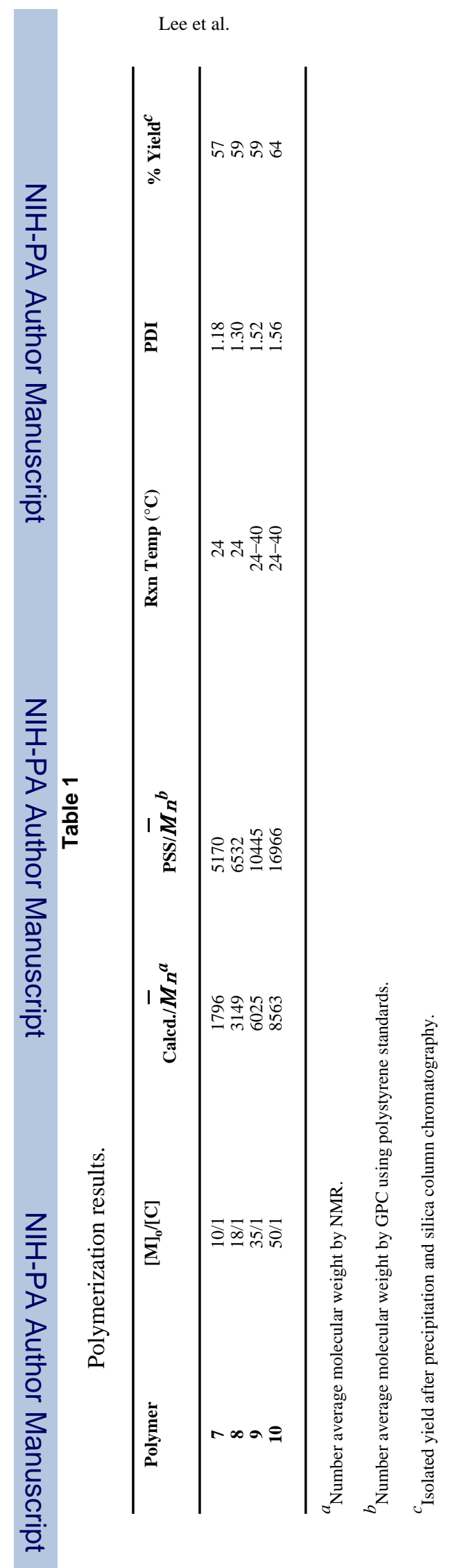

Page 8 